\title{
Noah's Ark and Internet Institutes: When and Why?
}

\section{Kuo-Chen Chou}

Gordon Life Science Institute, Boston, Massachusetts 02478, United States of America

Correspondence to: Kuo-Chen Chou, kcchou@gordonlifescience.org, kcchou38@gmail.com

Keywords: Pandemic COVID-19, The End of World, The Prophecy of Revelation in Bible, The Internet Institutes

Received: July 4, 2020 Accepted: July 12, $2020 \quad$ Published: July 15, 2020

Copyright $\odot 2020$ by author(s) and Scientific Research Publishing Inc.

This work is licensed under the Creative Commons Attribution International License (CC BY 4.0).

http://creativecommons.org/licenses/by/4.0/

\section{(c) (i) Open Access}

\section{ABSTRACT}

The damage of coronavirus to our Earth is unprecedented that is going to kill the entire human beings. Facing this kind of situation, there are two completely different kinds of viewpoints. According to the philosophy of "Atheists" Karl Max and Friedrich Engels, "there is a Bigging, there must be an End", meaning our Earth will eventually collide with the other planet and be destroyed completely. According to Holly Bible, however, Jesus, will come down again to bring Godly people to the Heaven and leave the remaining in the coronavirus-hell. During this waiting period, the "Internet Institutes" can provide the most useful knowledge for the other planets.

\section{INTRODUCTION}

As of July-03-2020, more than 230 countries on the Earth have been attacked by the coronavirus disease 2019 (COVID-19): for USA alone with reported 2,803,454 cases of which 130,995 result in deaths; for United Kingdom with 283,757 cases and 43,995 to deaths.

\section{FACTS AND DISCUSSIONS}

The damage power of COVID-19 is overwhelmingly stronger than "atomic bombs" ( $2^{\text {nd }}$ World War, 1945) or any kind of terrorists ("911", 2001). The death number has also far beyond the reach of the death of military persons killed in any of war involved with USA.

Obviously, the unprecedented power must come from God and certainly not from human beings.

Coronavirus disease 2019 (COVID-19) is an infectious disease caused by severe acute respiratory syndrome, which was first identified in December 2019 in Wuhan, Hubei, China. After April 2020 and causing about 4000 deaths, although no remarkable infectious cases reported in Wuhan. Unfortunately, the $2^{\text {nd }}$-wave coronavirus diseases have been found on Beijing during May 2020. This kind of originally from "Eastern countries" to Western Countries" and then back from the West to the East, very much like playing "Tennis" or "ping-pong" ball. It is the "Coronavirus" for the ball.

Since all the scientists working in a sharing laboratory of the Universities or most conversional Institutes must wear masks except those working in the "Internet Institute" such as the "Gordon Life Scient 
Institute" [1,2]. And the results thus obtained will be of real usage for the other planet as indicated in [3] as well as widely and increasingly agreeable as supported by many papers from different angles or aspects, particularly for the idea of "Pseudo Amino Acid Composition" or PseAAC" [4-74], the "5-steps Rule" [75-97], the "Wenxiang Diagram" [98-100], the "HIV protease inhibitor prediction" [101-106], and the "Graphic Rules" [107-115]. Using graphic approaches to study biological and medical systems can provide an intuitive vision and useful insights for helping analyze complicated relations therein as shown by the eight master pieces of pioneering papers from the then Chairman of Nobel Prize Committee Sture Forsen (see, e.g., $[107,116]$ and many follow-up papers $[67,98,99,113,115,117-160]$.

\section{CONCLUSIONS}

For our Earth, after several waves of the killings as described in the Section 2, the time of its "End" will become much faster according to the exponential mode. Before its "End", it will provide the most useful knowledge to do the science with the "Internet Institutes".

\section{CONFLICTS OF INTEREST}

The author declares no conflicts of interest regarding the publication of this paper.

\section{REFERENCES}

1. Chou, K.C. (2019) The Cradle of Gordon Life Science Institute and Its Development and Driving Force. Biomedical Journal of Scientific \& Technical Research, 23, Article ID: 17848.

2. Chou, K.C. (2019) Intriguing Story about the Birth of Gordon Life Science Institute and Its Development and Driving Force. Journal of Retro Virology and Anti Retro Virology, 1, Article ID: 180002.

3. Chou, K.C. (2020) The Development of Gordon Life Science Institute: Its Driving Force and Accomplishments. Natural Science, 12, 202-217. https://doi.org/10.4236/ns.2020.124018

4. Hayat, M. and Khan, A. (2012) Discriminating Outer Membrane Proteins with Fuzzy K-Nearest Neighbor Algorithms Based on the General Form of Chou's PseAAC. Protein \& Peptide Letters, 19, 411-421. https://doi.org/10.2174/092986612799789387

5. Liao, B., Xiang, Q. and Li, D. (2012) Incorporating Secondary Features into the General form of Chou's PseAAC for Predicting Protein Structural Class. Protein \& Peptide Letters, 19, 1133-1138. https://doi.org/10.2174/092986612803217051

6. Mei, S. (2012) Multi-Kernel Transfer Learning Based on Chou's PseAAC Formulation for Protein Submitochondria Localization. Journal of Theoretical Biology, 293, 121-130. https://doi.org/10.1016/j.jtbi.2011.10.015

7. Mei, S. (2012) Predicting Plant Protein Subcellular Multi-Localization by Chou's PseAAC Formulation Based Multi-Label Homolog Knowledge Transfer Learning. Journal of Theoretical Biology, 310, 80-87. https://doi.org/10.1016/j.jtbi.2012.06.028

8. Qin, Y.F., Wang, C.H., Yu, X.Q., Zhu, J., Liu, T.G. and Zheng, X.Q. (2012) Predicting Protein Structural Class by Incorporating Patterns of Over-Represented k-mers into the General form of Chou's PseAAC. Protein \& Peptide Letters, 19, 388-397. https://doi.org/10.2174/092986612799789350

9. Sun, X.Y., Shi, S.P., Qiu, J.D., Suo, S.B., Huang, S.Y. and Liang, R.P. (2012) Identifying Protein Quaternary Structural Attributes by Incorporating Physicochemical Properties into the General Form of Chou's PseAAC via Discrete Wavelet Transform. Molecular BioSystems, 8, 3178-3184. https://doi.org/10.1039/c2mb25280e

10. Cao, D.S., Xu, Q.S. and Liang, Y.Z. (2013) propy: A Tool to Generate Various Modes of Chou's PseAAC. Bioinformatics, 29, 960-962. https://doi.org/10.1093/bioinformatics/btt072

11. Chang, T.H., Wu, L.C., Lee, T.Y., Chen, S.P., Huang, H.D. and Horng, J.T. (2013) EuLoc: A Web-Server for 
Accurately Predict Protein Subcellular Localization in Eukaryotes by Incorporating Various Features of Sequence Segments into the General Form of Chou's PseAAC. Journal of Computer-Aided Molecular Design, 27, 91-103. https://doi.org/10.1007/s10822-012-9628-0

12. Fan, G.-L., Li, Q.-Z. and Zuo, Y.-C. (2013) Predicting Acidic and Alkaline Enzymes by Incorporating the Average Chemical Shift and Gene Ontology Informations into the General Form of Chou's PseAAC. Process Biochemistry, 48, 1048-1053. https://doi.org/10.1016/j.procbio.2013.05.012

13. Pacharawongsakda, E. and Theeramunkong, T. (2013) Predict Subcellular Locations of Singleplex and Multiplex Proteins by Semi-Supervised Learning and Dimension-Reducing General Mode of Chou's PseAAC. IEEE Transactions on Nanobioscience, 12, 311-320. https://doi.org/10.1109/TNB.2013.2272014

14. Xie, H.L., Fu, L. and Nie, X.D. (2013) Using Ensemble SVM to Identify Human GPCRs N-Linked Glycosylation Sites Based on the General Form of Chou's PseAAC. Protein Engineering, Design and Selection, 26, 735-742. https://doi.org/10.1093/protein/gzt042

15. Han, G.S., Yu, Z.G. and Anh, V. (2014) A Two-Stage SVM Method to Predict Membrane Protein Types by Incorporating Amino Acid Classifications and Physicochemical Properties into a General Form of Chou's PseAAC. Journal of Theoretical Biology, 344, 31-39. https://doi.org/10.1016/j.jtbi.2013.11.017

16. Li, L., Yu, S., Xiao, W., Li, Y., Li, M., Huang, L., Zheng, X., Zhou, S. and Yang, H. (2014) Prediction of Bacterial Protein Subcellular Localization by Incorporating Various Features into Chou's PseAAC and a Backward Feature Selection Approach. Biochimie, 104, 100-107. https://doi.org/10.1016/j.biochi.2014.06.001

17. Zhang, J., Zhao, X., Sun, P. and Ma, Z. (2014) PSNO: Predicting Cysteine S-Nitrosylation Sites by Incorporating Various Sequence-Derived Features into the General Form of Chou's PseAAC. International Journal of Molecular Sciences, 15, 11204-11219. https://doi.org/10.3390/ijms150711204

18. Liu, B., Xu, J., Fan, S., Xu, R., Zhou, J. and Wang, X. (2015) PseDNA-Pro: DNA-Binding Protein Identification by Combining Chou's PseAAC and Physicochemical Distance Transformation. Molecular Informatics, 34, 8-17. https://doi.org/10.1002/minf.201400025

19. Mandal, M., Mukhopadhyay, A. and Maulik, U. (2015) Prediction of Protein Subcellular Localization by Incorporating Multiobjective PSO-Based Feature Subset Selection into the General Form of Chou's PseAAC. Medical \& Biological Engineering \& Computing, 53, 331-344. https://doi.org/10.1007/s11517-014-1238-7

20. Sanchez, V., Peinado, A.M., Perez-Cordoba, J.L. and Gomez, A.M. (2015) A New Signal Characterization and Signal-Based Chou's PseAAC Representation of Protein Sequences. Journal of Bioinformatics and Computational Biology, 13, Article ID: 1550024. https://doi.org/10.1142/S0219720015500249

21. Kabir, M. and Hayat, M. (2016) iRSpot-GAEnsC: Identifying Recombination Spots via Ensemble Classifier and Extending the Concept of Chou's PseAAC to Formulate DNA Samples. Molecular Genetics and Genomics, 291, 285-296. https://doi.org/10.1007/s00438-015-1108-5

22. Tahir, M. and Hayat, M. (2016) iNuc-STNC: A Sequence-Based Predictor for Identification of Nucleosome Positioning in Genomes by Extending the Concept of SAAC and Chou's PseAAC. Molecular BioSystems, 12, 2587-2593. https://doi.org/10.1039/C6MB00221H

23. Ju, Z. and He, J.J. (2017) Prediction of Lysine Propionylation Sites Using Biased SVM and Incorporating Four Different Sequence Features into Chou's PseAAC. Journal of Molecular Graphics and Modelling, 76, 356-363. https://doi.org/10.1016/j.jmgm.2017.07.022

24. Yu, B., Li, S., Qiu, W.Y., Chen, C., Chen, R.X., Wang, L., Wang, M.H. and Zhang, Y. (2017) Accurate Prediction of Subcellular Location of Apoptosis Proteins Combining Chou's PseAAC and PsePSSM Based on Wavelet Denoising. Oncotarget, 8, 107640-107665. https://doi.org/10.18632/oncotarget.22585

25. Ahmad, J. and Hayat, M. (2018) MFSC: Multi-Voting Based Feature Selection for Classification of Golgi Pro- 
teins by Adopting the General Form of Chou's PseAAC Components. Journal of Theoretical Biology, 463, 99-109. https://doi.org/10.1016/j.jtbi.2018.12.017

26. Akbar, S. and Hayat, M. (2018) iMethyl-STTNC: Identification of $\mathrm{N}^{6}$-Methyladenosine Sites by Extending the Idea of SAAC into Chou's PseAAC to Formulate RNA Sequences. Journal of Theoretical Biology, 455, 205-211. https://doi.org/10.1016/j.jtbi.2018.07.018

27. Contreras-Torres, E. (2018) Predicting Structural Classes of Proteins by Incorporating Their Global and Local Physicochemical and Conformational Properties into General Chou's PseAAC. Journal of Theoretical Biology, 454, 139-145. https://doi.org/10.1016/j.jtbi.2018.05.033

28. Fu, X., Zhu, W., Liso, B., Cai, L., Peng, L. and Yang, J. (2018) Improved DNA-Binding Protein Identification by Incorporating Evolutionary Information into the Chou's PseAAC. IEEE Access, 6, 66545-66556. https://doi.org/10.1109/ACCESS.2018.2876656

29. Javed, F. and Hayat, M. (2018) Predicting Subcellular Localizations of Multi-Label Proteins by Incorporating the Sequence Features into Chou's PseAAC. Genomics, 111, 1325-1332. https://doi.org/10.1016/j.ygeno.2018.09.004

30. Mousavizadegan, M. and Mohabatkar, H. (2018) Computational Prediction of Antifungal Peptides via Chou's PseAAC and SVM. Journal of Bioinformatics and Computational Biology, 16, Article ID: 1850016. https://doi.org/10.1142/S0219720018500166

31. Zhang, S. and Liang, Y. (2018) Predicting Apoptosis Protein Subcellular Localization by Integrating Auto-Cross Correlation and PSSM into Chou's PseAAC. Journal of Theoretical Biology, 457, 163-169.

https://doi.org/10.1016/j.jtbi.2018.08.042

32. Ahmad, J. and Hayat, M. (2019) MFSC: Multi-Voting Based Feature Selection for Classification of Golgi Proteins by Adopting the General Form of Chou's PseAAC Components. Journal of Theoretical Biology, 463, 99-109. https://doi.org/10.1016/j.jtbi.2018.12.017

33. Butt, A.H., Rasool, N. and Khan, Y.D. (2019) Prediction of Antioxidant Proteins by Incorporating Statistical Moments Based Features into Chou's PseAAC. Journal of Theoretical Biology, 473, 1-8.

https://doi.org/10.1016/j.jtbi.2019.04.019

34. Javed, F. and Hayat, M. (2019) Predicting Subcellular Localization of Multi-Label Proteins by Incorporating the Sequence Features into Chou's PseAAC. Genomics, 111, 1325-1332. https://doi.org/10.1016/j.ygeno.2018.09.004

35. Tahir, M., Hayat, M. and Khan, S.A. (2019) iNuc-ext-PseTNC: An Efficient Ensemble Model for Identification of Nucleosome Positioning by Extending the Concept of Chou's PseAAC to Pseudo-Tri-Nucleotide Composition. Molecular Genetics and Genomics, 294, 199-210. https://doi.org/10.1007/s00438-018-1498-2

36. Hayat, M. and Iqbal, N. (2014) Discriminating Protein Structure Classes by Incorporating Pseudo Average Chemical Shift to Chou's General PseAAC and Support Vector Machine. Computer Methods and Programs in Biomedicine, 116, 184-192. https://doi.org/10.1016/j.cmpb.2014.06.007

37. Ahmad, S., Kabir, M. and Hayat, M. (2015) Identification of Heat Shock Protein Families and J-Protein Types by Incorporating Dipeptide Composition into Chou's General PseAAC. Computer Methods and Programs in Biomedicine, 122, 165-174. https://doi.org/10.1016/j.cmpb.2015.07.005

38. Dehzangi, A., Heffernan, R., Sharma, A., Lyons, J., Paliwal, K. and Sattar, A. (2015) Gram-Positive and Gram-Negative Protein Subcellular Localization by Incorporating Evolutionary-Based Descriptors into Chou's General PseAAC. Journal of Theoretical Biology, 364, 284-294. https://doi.org/10.1016/j.jtbi.2014.09.029

39. Sharma, R., Dehzangi, A., Lyons, J., Paliwal, K., Tsunoda, T. and Sharma, A. (2015) Predict Gram-Positive and Gram-Negative Subcellular Localization via Incorporating Evolutionary Information and Physicochemical Features Into Chou's General PseAAC. IEEE Transactions on NanoBioscience, 14, 915-926.

https://doi.org/10.1109/TNB.2015.2500186 
40. Zhang, M., Zhao, B. and Liu, X. (2015) Predicting Industrial Polymer Melt Index via Incorporating Chaotic Characters into Chou's General PseAAC. Chemometrics and Intelligent Laboratory Systems, 146, 232-240. https://doi.org/10.1016/j.chemolab.2015.05.028

41. Zhang, S.L. (2015) Accurate Prediction of Protein Structural Classes by Incorporating PSSS and PSSM into Chou's General PseAAC. Chemometrics and Intelligent Laboratory Systems, 142, 28-35. https://doi.org/10.1016/j.chemolab.2015.01.004

42. Ahmad, K., Waris, M. and Hayat, M. (2016) Prediction of Protein Submitochondrial Locations by Incorporating Dipeptide Composition into Chou's General Pseudo Amino Acid Composition. The Journal of Membrane Biology, 249, 293-304. https://doi.org/10.1007/s00232-015-9868-8

43. Behbahani, M., Mohabatkar, H. and Nosrati, M. (2016) Analysis and Comparison of Lignin Peroxidases between Fungi and Bacteria Using Three Different Modes of Chou's General Pseudo Amino Acid Composition. Journal of Theoretical Biology, 411, 1-5. https://doi.org/10.1016/j.jtbi.2016.09.001

44. Fan, G.L., Liu, Y.L. and Wang, H. (2016) Identification of Thermophilic Proteins by Incorporating Evolutionary and Acid Dissociation Information into Chou's General Pseudo Amino Acid Composition. Journal of Theoretical Biology, 407, 138-142. https://doi.org/10.1016/j.jtbi.2016.07.010

45. Ju, Z., Cao, J.Z. and Gu, H. (2016) Predicting Lysine Phosphoglycerylation with Fuzzy SVM by Incorporating k-Spaced Amino Acid Pairs into Chou’s General PseAAC. Journal of Theoretical Biology, 397, 145-150. https://doi.org/10.1016/j.jtbi.2016.02.020

46. Tiwari, A.K. (2016) Prediction of G-Protein Coupled Receptors and Their Subfamilies by Incorporating Various Sequence Features into Chou's General PseAAC. Computer Methods and Programs in Biomedicine, 134, 197-213. https://doi.org/10.1016/j.cmpb.2016.07.004

47. Xu, C., Sun, D., Liu, S. and Zhang, Y. (2016) Protein Sequence Analysis by Incorporating Modified Chaos Game and Physicochemical Properties into Chou's General Pseudo Amino Acid Composition. Journal of Theoretical Biology, 406, 105-115. https://doi.org/10.1016/j.jtbi.2016.06.034

48. Zou, H.L. and Xiao, X. (2016) Classifying Multifunctional Enzymes by Incorporating Three Different Models into Chou's General Pseudo Amino Acid Composition. The Journal of Membrane Biology, 249, 551-557. https://doi.org/10.1007/s00232-016-9904-3

49. Jiao, Y.S. and Du, P.F. (2017) Predicting Protein Submitochondrial Locations by Incorporating the Positional-Specific Physicochemical Properties into Chou's General Pseudo-Amino Acid Compositions. Journal of Theoretical Biology, 416, 81-87. https://doi.org/10.1016/j.jtbi.2016.12.026

50. Ju, Z. and He, J.J. (2017) Prediction of Lysine Crotonylation Sites by Incorporating the Composition of k-Spaced Amino Acid Pairs into Chou's General PseAAC. Journal of Molecular Graphics and Modelling, 77, 200-204. https://doi.org/10.1016/j.jmgm.2017.08.020

51. Khan, M., Hayat, M., Khan, S.A. and Iqbal, N. (2017) Unb-DPC: Identify Mycobacterial Membrane Protein Types by Incorporating Un-Biased Dipeptide Composition into Chou's General PseAAC. Journal of Theoretical Biology, 415, 13-19. https://doi.org/10.1016/j.jtbi.2016.12.004

52. Liang, Y. and Zhang, S. (2017) Predict Protein Structural Class by Incorporating Two Different Modes of Evolutionary Information into Chou's General Pseudo Amino Acid Composition. Journal of Molecular Graphics and Modelling, 78, 110-117. https://doi.org/10.1016/j.jmgm.2017.10.003

53. Meher, P.K., Sahu, T.K., Saini, V. and Rao, A.R. (2017) Predicting Antimicrobial Peptides with Improved Accuracy by Incorporating the Compositional, Physico-Chemical and Structural Features into Chou's General PseAAC. Scientific Reports, 7, Article No. 42362. https://doi.org/10.1038/srep42362

54. Qiu, W.R., Zheng, Q.S., Sun, B.Q. and Xiao, X. (2017) Multi-iPPseEvo: A Multi-Label Classifier for Identifying 
Human Phosphorylated Proteins by Incorporating Evolutionary Information into Chou's General PseAAC via Grey System Theory. Molecular Informatics, 36, Article ID: 1600085. https://doi.org/10.1002/minf.201600085

55. Xu, C., Ge, L., Zhang, Y., Dehmer, M. and Gutman, I. (2017) Prediction of Therapeutic Peptides by Incorporating q-Wiener Index into Chou's General PseAAC. Journal of Biomedical Informatics, 75, 63-69.

56. Butt, A.H., Rasool, N. and Khan, Y.D. (2018) Predicting Membrane Proteins and Their Types by Extracting Various Sequence Features into Chou's General PseAAC. Molecular Biology Reports, 45, 2295-2306. https://doi.org/10.1007/s11033-018-4391-5

57. Ghauri, A.W., Khan, Y.D., Rasool, N., Khan, S.A. and Chou, K.C. (2018) pNitro-Tyr-PseAAC: Predict Nitrotyrosine Sites in Proteins by Incorporating Five Features into Chou's General PseAAC. Current Pharmaceutical Design, 24, 4034-4043. https://doi.org/10.2174/1381612825666181127101039

58. Ju, Z. and Wang, S.Y. (2018) Prediction of Citrullination Sites by Incorporating k-Spaced Amino Acid Pairs into Chou's General Pseudo Amino Acid Composition. Gene, 664, 78-83. https://doi.org/10.1016/j.gene.2018.04.055

59. Krishnan, M.S. (2018) Using Chou's General PseAAC to Analyze the Evolutionary Relationship of Receptor Associated Proteins (RAP) with Various Folding Patterns of Protein Domains. Journal of Theoretical Biology, 445, 62-74. https://doi.org/10.1016/j.jtbi.2018.02.008

60. Liang, Y. and Zhang, S. (2018) Identify Gram-Negative Bacterial Secreted Protein Types by Incorporating Different Modes of PSSM into Chou's General PseAAC via Kullback-Leibler Divergence. Journal of Theoretical Biology, 454, 22-29. https://doi.org/10.1016/j.jtbi.2018.05.035

61. Mei, J., Fu, Y. and Zhao, J. (2018) Analysis and Prediction of Ion Channel Inhibitors by Using Feature Selection and Chou's General Pseudo Amino Acid Composition. Journal of Theoretical Biology, 456, 41-48. https://doi.org/10.1016/j.jtbi.2018.07.040

62. Mei, J. and Zhao, J. (2018) Analysis and Prediction of Presynaptic and Postsynaptic Neurotoxins by Chou's General Pseudo Amino Acid Composition and Motif Features. Journal of Theoretical Biology, 427, 147-153. https://doi.org/10.1016/j.jtbi.2018.03.034

63. Rahman, S.M., Shatabda, S., Saha, S., Kaykobad, M. and Sohel Rahman, M. (2018) DPP-PseAAC: A DNA-Binding Protein Prediction Model Using Chou's General PseAAC. Journal of Theoretical Biology, 452, 22-34. https://doi.org/10.1016/j.jtbi.2018.05.006

64. Sankari, E.S. and Manimegalai, D.D. (2018) Predicting Membrane Protein Types by Incorporating a Novel Feature Set into Chou's General PseAAC. Journal of Theoretical Biology, 455, 319-328.

https://doi.org/10.1016/j.jtbi.2018.07.032

65. Srivastava, A., Kumar, R. and Kumar, M. (2018) BlaPred: Predicting and Classifying Beta-Lactamase Using a 3-Tier Prediction System via Chou's General PseAAC. Journal of Theoretical Biology, 457, 29-36. https://doi.org/10.1016/j.jtbi.2018.08.030

66. Zhang, S. and Duan, X. (2018) Prediction of Protein Subcellular Localization with Oversampling Approach and Chou's General PseAAC. Journal of Theoretical Biology, 437, 239-250. https://doi.org/10.1016/j.jtbi.2017.10.030

67. Adilina, S., Farid, D.M. and Shatabda, S. (2019) Effective DNA Binding Protein Prediction by Using Key Features via Chou's General PseAAC. Journal of Theoretical Biology, 460, 64-78.

https://doi.org/10.1016/j.jtbi.2018.10.027

68. Behbahani, M., Nosrati, M., Moradi, M. and Mohabatkar, H. (2019) Using Chou's General Pseudo Amino Acid Composition to Classify Laccases from Bacterial and Fungal Sources via Chou's Five-Step Rule. Applied Biochemistry and Biotechnology, 190, 1035-1048. https://doi.org/10.1007/s12010-019-03141-8

69. Chen, G., Cao, M., Yu, J., Guo, X. and Shi, S. (2019) Prediction and Functional Analysis of Prokaryote Lysine Acetylation Site by Incorporating Six Types of Features into Chou's General PseAAC. Journal of Theoretical Bi- 
ology, 461, 92-101. https://doi.org/10.1016/j.jtbi.2018.10.047

70. Nazari, I., Tahir, M., Tayari, H. and Chong, K.T. (2019) iN6-Methyl (5-Step): Identifying RNA N6-Methyladenosine Sites Using Deep Learning Mode via Chou's 5-Step Rules and Chou's General PseKNC. Chemometrics and Intelligent Laboratory Systems, 193, Article ID: 103811. https://doi.org/10.1016/j.chemolab.2019.103811

71. Shen, Y., Tang, J. and Guo, F. (2019) Identification of Protein Subcellular Localization via Integrating Evolutionary and Physicochemical Information into Chou's General PseAAC. Journal of Theoretical Biology, 462, 230-239. https://doi.org/10.1016/j.jtbi.2018.11.012

72. Wang, L., Zhang, R. and Mu, Y. (2019) Fu-SulfPred: Identification of Protein S-Sulfenylation Sites by Fusing Forests via Chou's General PseAAC. Journal of Theoretical Biology, 461, 51-58. https://doi.org/10.1016/j.jtbi.2018.10.046

73. Xiao, X., Cheng, X., Chen, G., Mao, Q. and Chou, K.C. (2019) pLoc_bal-mVirus: Predict Subcellular Localization of Multi-Label Virus Proteins by Chou's General PseAAC and IHTS Treatment to Balance Training Dataset. Medicinal Chemistry, 15, 496-509. https://doi.org/10.2174/1573406415666181217114710

74. Behbahani, M., Nosrati, M., Moradi, M. and Mohabatkar, H. (2020) Using Chou's General Pseudo Amino Acid Composition to Classify Laccases from Bacterial and Fungal Sources via Chou's Five-Step Rule. Applied Biochemistry and Biotechnology, 190, 1035-1048. https://doi.org/10.1007/s12010-019-03141-8

75. Chen, Y. and Fan, X. (2019) Use Chou's 5-Steps Rule to Reveal Active Compound and Mechanism of Shuangsheng Pingfei San on Idiopathic Pulmonary Fibrosis. Current Molecular Medicine, 20, 220-230.

https://doi.org/10.2174/1566524019666191011160543

76. Du, X., Diao, Y., Liu, H. and Li, S. (2019) MsDBP: Exploring DNA-Binding Proteins by Integrating Multi-Scale Sequence Information via Chou's 5-Steps Rule. Journal of Proteome Research, 18, 3119-3132.

https://doi.org/10.1021/acs.jproteome.9b00226

77. Dutta, A., Dalmia, A., A. R, Singh, K.K. and Anand, A. (2019) Using the Chou's 5-Steps Rule to Predict Splice Junctions with Interpretable Bidirectional Long Short-Term Memory Networks. Computers in Biology and Medicine, 116, Article ID: 103558. https://doi.org/10.1016/j.compbiomed.2019.103558

78. Hussain, W., Khan, S.D., Rasool, N., Khan, S.A. and Chou, K.C. (2019) SPalmitoylC-PseAAC: A Sequence-Based Model Developed via Chou's 5-Steps Rule and General PseAAC for Identifying S-Palmitoylation Sites in Proteins. Analytical Biochemistry, 568, 14-23. https://doi.org/10.1016/j.ab.2018.12.019

79. Hussain, W., Khan, Y.D., Rasool, N., Khan, S.A. and Chou, K.C. (2019) SPrenylC-PseAAC: A Sequence-Based Model Developed via Chou's 5-Steps Rule and General PseAAC for Identifying S-Prenylation Sites in Proteins. Journal of Theoretical Biology, 468, 1-11. https://doi.org/10.1016/j.jtbi.2019.02.007

80. Jun, Z. and Wang, S.Y. (2019) Identify Lysine Neddylation Sites Using Bi-Profile Bayes Feature Extraction via the Chou's 5-Steps Rule and General Pseudo Components. Current Genomics, 20, 592-601. https://doi.org/10.2174/1389202921666191223154629

81. Khan, S., Khan, M., Iqbal, N., Hussain, T., Khan, S.A. and Chou, K.C. (2020) A Two-Level Computation Model Based on Deep Learning Algorithm for Identification of piRNA and Their Functions via Chou's 5-Steps Rule. International Journal of Peptide Research and Therapeutics, 26, 795-809.

https://doi.org/10.1007/s10989-019-09887-3

82. Lan, J., Liu, J., Liao, C., Merkler, D.J., Han, Q. and Li, J. (2019) A Study for Therapeutic Treatment against Parkinson's Disease via Chou's 5-Steps Rule. Current Topics in Medicinal Chemistry, 19, 2318-2333.

http://www.eurekaselect.com/175887/article https://doi.org/10.2174/1568026619666191019111528

83. Liang, R., Xie, J., Zhang, C., Zhang, M., Huang, H., Huo, H., Cao, X. and Niu, B. (2019) Identifying Cancer Tar- 
gets Based on Machine Learning Methods via Chou's 5-Steps Rule and General Pseudo Components. Current Topics in Medicinal Chemistry, 19, 2301-2317. https://doi.org/10.2174/1568026619666191016155543

84. Liang, Y. and Zhang, S. (2019) Identifying DNase I Hypersensitive Sites Using Multi-Features Fusion and F-Score Features Selection via Chou's 5-Steps Rule. Biophysical Chemistry, 253, Article ID: 106227. https://doi.org/10.1016/j.bpc.2019.106227

85. Wiktorowicz, A., Wit, A., Dziewierz, A., Rzeszutko, L., Dudek, D. and Kleczynski, P. (2019) Calcium Pattern Assessment in Patients with Severe Aortic Stenosis via the Chou's 5-Steps Rule. Current Pharmaceutical Design, 25, 3769-3775. https://doi.org/10.2174/1381612825666190930101258

86. Yang, L., Lv, Y., Wang, S., Zhang, Q., Pan, Y., Su, D., Lu, Q. and Zuo, Y. (2019) Identifying FL11 Subtype by Characterizing Tumor Immune Microenvironment in Prostate Adenocarcinoma via Chou's 5-Steps Rule. Genomics, 112, 1500-1515. https://doi.org/10.1016/j.ygeno.2019.08.021

87. Akmal, M.A., Hussain, W., Rasool, N., Khan, Y.D., Khan, S.A. and Chou, K.C. (2020) Using Chou's 5-Steps Rule to Predict O-Linked Serine Glycosylation Sites by Blending Position Relative Features and Statistical Moment. IEEE/ ACM Transactions on Computational Biology and Bioinformatics, in press.

https://doi.org/10.1109/TCBB.2020.2968441

88. Charoenkwan, P., Schaduangrat, N., Nantasenamat, C., Piacham, T. and Shoombuatong, W. (2020) iQSP: A Sequence-Based Tool for the Prediction and Analysis of Quorum Sensing Peptides via Chou's 5-Steps Rule and Informative Physicochemical Properties. International Journal of Molecular Sciences, 21, 75. https://doi.org/10.3390/ijms21010075

89. Charoenkwan, P., Schaduangrat, N., Nantasenamat, C., Piacham, T. and Shoombuatong, W. (2020) Correction: Shoombuatong, W., et al. iQSP: A Sequence-Based Tool for the Prediction and Analysis of Quorum Sensing Peptides via Chou's 5-Steps Rule and Informative Physicochemical Properties. Int. J. Mol. Sci. 2020, 21, 75. International Journal of Molecular Sciences, 21, 2629. https://doi.org/10.3390/ijms21072629

90. Chen, Y. and Fan, X. (2020) Use of Chou's 5-Steps Rule to Reveal Active Compound and Mechanism of Shuangshen Pingfei San on Idiopathic Pulmonary Fibrosis. Current Molecular Medicine, 20, 220-230. https://doi.org/10.2174/1566524019666191011160543

91. Du, L., Meng, Q., Jiang, H. and Li, Y. (2020) Using Evolutionary Information and Multi-Label Linear Discriminant Analysis to Predict the Subcellular Location of Multi-Site Bacterial Proteins via Chou's 5-Steps Rule. IEEE Access, 8, 56452-56461. https://doi.org/10.1109/ACCESS.2020.2982160

92. Dutta, A., Dalmia, A., A. R, Singh, K.K. and Anand, A. (2020) Using the Chou's 5-Steps Rule to Predict Splice Junctions with Interpretable Bidirectional Long Short-Term Memory Networks. Computers in Biology and Medicine, 116, Article ID: 103558. https://doi.org/10.1016/j.compbiomed.2019.103558

93. Ju, Z. and Wang, S.Y. (2020) Prediction of Lysine Formylation Sites Using the Composition of k-Spaced Amino Acid Pairs via Chou's 5-Steps Rule and General Pseudo Components. Genomics, 112, 859-866. https://doi.org/10.1016/j.ygeno.2019.05.027

94. Kabir, M., Ahmad, S., Iqbal, M. and Hayat, M. (2020) iNR-2L: A Two-Level Sequence-Based Predictor Developed via Chou's 5-Steps Rule and General PseAAC for Identifying Nuclear Receptors and Their Families. Genomics, 112, 276-285. https://doi.org/10.1016/j.ygeno.2019.02.006

95. Lin, W., Xiao, X., Qiu, W. and Chou, K.C. (2020) Use Chou's 5-Steps Rule to Predict Remote Homology Proteins by Merging Grey Incidence Analysis and Domain Similarity Analysis. Natural Science, 12, 181-198. https://doi.org/10.4236/ns.2020.123016

96. Vundavilli, H., Datta, A., Sima, C., Hua, J., Lopes, R. and Bittner, M. (2020) Using Chou's 5-Steps Rule to Model Feedback in Lung Cancer. IEEE Journal of Biomedical and Health Informatics, 21, 1-24. https://doi.org/10.1109/JBHI.2019.2958042 
97. Yang, L., Lv, Y., Wang, S., Zhang, Q., Pan, Y., Su, D., Lu, Q. and Zuo, Y. (2020) Identifying FL11 Subtype by Characterizing Tumor Immune Microenvironment in Prostate Adenocarcinoma via Chou's 5-Steps Rule. Genomics, 112, 1500-1515. https://doi.org/10.1016/j.ygeno.2019.08.021

98. Chou, K.C., Lin, W.Z. and Xiao, X. (2011) Wenxiang: A Web-Server for Drawing Wenxiang Diagrams. Natural Science, 3, 862-865. https://doi.org/10.4236/ns.2011.310111

99. Zhou, G.P. (2011) The Disposition of the LZCC Protein Residues in Wenxiang Diagram Provides New Insights into the Protein-Protein Interaction Mechanism. Journal of Theoretical Biology, 284, 142-148.

https://doi.org/10.1016/j.jtbi.2011.06.006

100. Zhou, G.P., Chen, D., Liao, S. and Huang, R.B. (2016) Recent Progresses in Studying Helix-Helix Interactions in Proteins by Incorporating the Wenxiang Diagram into the NMR Spectroscopy. Current Topics in Medicinal Chemistry, 16, 581-590. https://doi.org/10.2174/1568026615666150819104617

101. Chou, K.C. (1993) A Vectorized Sequence-Coupling Model for Predicting HIV Protease Cleavage Sites in Proteins. The Journal of Biological Chemistry, 268, 16938-16948.

102. Chou, K.C. and Zhang, C.T. (1992) Diagrammatization of Codon Usage in 339 HIV Proteins and Its Biological Implication. AIDS Research and Human Retroviruses, 8, 1967-1976. https://doi.org/10.1089/aid.1992.8.1967

103. Chou, J.J. (1993) Predicting Cleavability of Peptide Sequences by HIV Protease via Correlation-Angle Approach. Journal of Protein Chemistry, 12, 291-302. https://doi.org/10.1007/BF01028191

104. Chou, K.C., Tomasselli, A.L., Reardon, I.M. and Heinrikson, R.L. (1996) Predicting HIV Protease Cleavage Sites in Proteins by a Discriminant Function Method. Proteins. Structure, Function, and Bioinformatics, 24, 51-72. https://doi.org/10.1002/(SICI) 1097-0134(199601)24:1<51::AID-PROT4>3.0.CO;2-R

105. Chou, K.C. and Zhang, C.T. (1993) Studies on the Specificity of HIV Protease: An Application of Markov Chain Theory. Journal of Protein Chemistry, 12, 709-724. https://doi.org/10.1007/BF01024929

106. Chou, K.C., Zhang, C.T. and Kezdy, F.J. (1993) A Vector Approach to Predicting HIV Protease Cleavage Sites in Proteins. Proteins. Structure, Function, and Bioinformatics, 16, 195-204. https://doi.org/10.1002/prot.340160206

107. Chou, K.C. and Forsen, S. (1980) Graphical Rules for Enzyme-Catalyzed Rate Laws. Biochemical Journal, 187, 829-835. https://doi.org/10.1042/bj1870829

108. Chou, K.C. (1981) A New Graphical Rule for Rate Laws of Enzyme Reactions with Branched Pathways. Canadian Journal of Biochemistry, 59, 757-761. https://doi.org/10.1139/o81-105

109. Chou, K.C., Carter, R.E. and Forsen, S. (1981) A New Graphical Method for Deriving Rate Equations for Complicated Mechanisms. Chemica Scripta, 18, 82-86.

110. Chou, K.C. and Forsen, S. (1981) Graphical Rules of Steady-State Reaction Systems. Canadian Journal of Chemistry, 59, 737-755. https://doi.org/10.1139/v81-107

111. Chou, K.C. and Liu, W.M. (1981) Graphical Rules for Non-Steady State Enzyme Kinetics. Journal of Theoretical Biology, 91, 637-654. https://doi.org/10.1016/0022-5193(81)90215-0

112. Chou, K.C. (1983) Advances in Graphical Methods of Enzyme Kinetics. Biophysical Chemistry, 17, 51-55. https://doi.org/10.1016/0301-4622(83)87013-6

113. Chou, K.C. (1989) Graphic Rules in Steady and Non-Steady Enzyme Kinetics. The Journal of Biological Chemistry, 264, 12074-12079.

114. Chou, K.C. (1993) Graphic Rule for Non-Steady-State Enzyme Kinetics and Protein Folding Kinetics. Journal of Mathematical Chemistry, 12, 97-108. https://doi.org/10.1007/BF01164628

115. Chou, K.C. (2010) Graphic Rule for Drug Metabolism Systems. Current Drug Metabolism, 11, 369-378. https://doi.org/10.2174/138920010791514261 
116. Chou, K.C. and Forsen, S. (1980) Diffusion-Controlled Effects in Reversible Enzymatic Fast Reaction System: Critical Spherical Shell and Proximity Rate Constants. Biophysical Chemistry, 12, 255-263. https://doi.org/10.1016/0301-4622(80)80002-0

117. Chou, K.C. (1983) Low-Frequency Vibrations of Helical Structures in Protein Molecules. Biochemical Journal, 209, 573-580. https://doi.org/10.1042/bj2090573

118. Chou, K.C. (1983) Identification of Low-Frequency Modes in Protein Molecules. Biochemical Journal, 215, 465-469. https://doi.org/10.1042/bj2150465

119. Zhou, G.P. and Deng, M.H. (1984) An Extension of Chou's Graphic Rules for Deriving Enzyme Kinetic Equations to Systems Involving Parallel Reaction Pathways. Biochemical Journal, 222, 169-176. https://doi.org/10.1042/bj2220169

120. Chou, K.C. (1984) Biological Functions of Low-Frequency Vibrations (Phonons). III. Helical Structures and Microenvironment. Biophysical Journal, 45, 881-889. https://doi.org/10.1016/S0006-3495(84)84234-4

121. Chou, K.C. (1984) The Biological Functions of Low-Frequency Phonons. 4. Resonance Effects and Allosteric Transition. Biophysical Chemistry, 20, 61-71. https://doi.org/10.1016/0301-4622(84)80005-8

122. Chou, K.C. (1984) Low-Frequency Vibrations of DNA Molecules. Biochemical Journal, 221, 27-31. https://doi.org/10.1042/bj2210027

123. Chou, K.C. (1985) Low-Frequency Motions in Protein Molecules: Beta-Sheet and Beta-Barrel. Biophysical Journal, 48, 289-297. https://doi.org/10.1016/S0006-3495(85)83782-6

124. Chou, K.C. (1985) Prediction of a Low-Frequency Mode in Bovine Pancreatic Trypsin Inhibitor Molecule. International Journal of Biological Macromolecules, 7, 77-80. https://doi.org/10.1016/0141-8130(85)90035-2

125. Chou, K.C. and Kiang, Y.S. (1985) The Biological Functions of Low-Frequency Phonons: 5. A Phenomenological Theory. Biophysical Chemistry, 22, 219-235. https://doi.org/10.1016/0301-4622(85)80045-4

126. Chou, K.C. (1986) Origin of Low-Frequency Motion in Biological Macromolecules: A View of Recent Progress of Quasi-Continuity Model. Biophysical Chemistry, 25, 105-116. https://doi.org/10.1016/0301-4622(86)87001-6

127. Chou, K.C. (1987) The Biological Functions of Low-Frequency Phonons: 6. A Possible Dynamic Mechanism of Allosteric Transition in Antibody Molecules. Biopolymers, 26, 285-295. https://doi.org/10.1002/bip.360260209

128. Chou, K.C. (1988) Review: Low-Frequency Collective Motion in Biomacromolecules and Its Biological Functions. Biophysical Chemistry, 30, 3-48. https://doi.org/10.1016/0301-4622(88)85002-6

129. Chou, K.C. and Maggiora, G.M. (1988) The Biological Functions of Low-Frequency Phonons: 7. The Impetus for DNA to Accommodate Intercalators. British Polymer Journal, 20, 143-148. https://doi.org/10.1002/pi.4980200209

130. Chou, K.C. (1989) Low-Frequency Resonance and Cooperativity of Hemoglobin. Trends in Biochemical Sciences, 14, 212-213. https://doi.org/10.1016/0968-0004(89)90026-1

131. Chou, K.C., Maggiora, G.M. and Mao, B. (1989) Quasi-Continuum Models of Twist-Like and Accordion-Like Low-Frequency Motions in DNA. Biophysical Journal, 56, 295-305. https://doi.org/10.1016/S0006-3495(89)82676-1

132. Chou, K.C. (1990) Review: Applications of Graph Theory to Enzyme Kinetics and Protein Folding Kinetics. Steady and Non-Steady State Systems. Biophysical Chemistry, 35, 1-24. https://doi.org/10.1016/0301-4622(90)80056-D

133. Althaus, I.W., Chou, J.J., Gonzales, A.J., Diebel, M.R., Chou, K.C., Kezdy, F.J., Romero, D.L., Aristoff, P.A., Tarpley, W.G. and Reusser, F. (1993) Steady-State Kinetic Studies with the Non-Nucleoside HIV-1 Reverse Transcriptase Inhibitor U-87201E. The Journal of Biological Chemistry, 268, 6119-6124.

134. Althaus, I.W., Gonzales, A.J., Chou, J.J., Diebel, M.R., Chou, K.C., Kezdy, F.J., Romero, D.L., Aristoff, P.A., 
Tarpley, W.G. and Reusser, F. (1993) The Quinoline U-78036 Is a Potent Inhibitor of HIV-1 Reverse Transcriptase. The Journal of Biological Chemistry, 268, 14875-14880.

135. Althaus, I.W., Chou, J.J., Gonzales, A.J., Diebel, M.R., Chou, K.C., Kezdy, F.J., Romero, D.L., Aristoff, P.A., Tarpley, W.G. and Reusser, F. (1993) Kinetic Studies with the Nonnucleoside HIV-1 Reverse Transcriptase Inhibitor U-88204E. Biochemistry, 32, 6548-6554. https://doi.org/10.1021/bi00077a008

136. Althaus, I.W., Chou, J.J., Gonzales, A.J., Diebel, M.R., Chou, K.C., Kezdy, F.J., Romero, D.L., Aristoff, P.A., Tarpley, W.G. and Reusser, F. (1994) Steady-State Kinetic Studies with the Polysulfonate U-9843, an HIV Reverse Transcriptase Inhibitor. Experientia, 50, 23-28. https://doi.org/10.1007/BF01992044

137. Althaus, I.W., Chou, J.J., Gonzales, A.J., Diebel, M.R., Chou, K.C., Kezdy, F.J., Romero, D.L., Thomas, R.C., Aristoff, P.A., Tarpley, W.G. and Reusser, F. (1994) Kinetic Studies with the Non-Nucleoside Human Immunodeficiency Virus Type-1 Reverse Transcriptase Inhibitor U-90152E. Biochemical Pharmacology, 47, 2017-2028. https://doi.org/10.1016/0006-2952(94)90077-9

138. Chou, K.C., Kezdy, F.J. and Reusser, F. (1994) Review: Kinetics of Processive Nucleic Acid Polymerases and Nucleases. Analytical Biochemistry, 221, 217-230. https://doi.org/10.1006/abio.1994.1405

139. Chou, K.C., Zhang, C.T. and Maggiora, G.M. (1994) Solitary Wave Dynamics as a Mechanism for Explaining the Internal Motion during Microtubule Growth. Biopolymers, 34, 143-153.

https://doi.org/10.1002/bip.360340114

140. Althaus, I.W., Chou, K.C., Franks, K.M., Diebel, M.R., Kezdy, F.J., Romero, D.L., Thomas, R.C., Aristoff, P.A., Tarpley, W.G. and Reusser, F. (1996) The Benzylthio-Pyrididine U-31,355, a Potent Inhibitor of HIV-1 Reverse Transcriptase. Biochemical Pharmacology, 51, 743-750. https://doi.org/10.1016/0006-2952(95)02390-9

141. Liu, H., Wang, M. and Chou, K.C. (2005) Low-Frequency Fourier Spectrum for Predicting Membrane Protein Types. Biochemical and Biophysical Research Communications (BBRC), 336, 737-739. https://doi.org/10.1016/j.bbrc.2005.08.160

142. Gordon, G. (2007) Designed Electromagnetic Pulsed Therapy: Clinical Applications. Journal of Cellular Physiology, 212, 579-582. https://doi.org/10.1002/jcp.21025

143. Andraos, J. (2008) Kinetic Plasticity and the Determination of Product Ratios for Kinetic Schemes Leading to Multiple Products without Rate Laws: New Methods Based on Directed Graphs. Canadian Journal of Chemistry, 86, 342-357. https://doi.org/10.1139/v08-020

144. Chou, K.C. and Shen, H.B. (2009) FoldRate: A Web-Server for Predicting Protein Folding Rates from Primary Sequence. The Open Bioinformatics Journal, 3, 31-50. https://doi.org/10.2174/1875036200903010031

145. Shen, H.B., Song, J.N. and Chou, K.C. (2009) Prediction of Protein Folding Rates from Primary Sequence by Fusing Multiple Sequential Features. Journal of Biomedical Science and Engineering (JBiSE), 2, 136-143. https://doi.org/10.4236/jbise.2009.23024

146. Wang, J.F. and Chou, K.C. (2009) Insight into the Molecular Switch Mechanism of Human Rab5a from Molecular Dynamics Simulations. Biochemical and Biophysical Research Communications (BBRC), 390, 608-612. https://doi.org/10.1016/j.bbrc.2009.10.014

147. Gordon, G. (2008) Extrinsic Electromagnetic Fields, Low Frequency (Phonon) Vibrations, and Control of Cell Function: A Non-Linear Resonance System. Journal of Biomedical Science and Engineering (JBiSE), 1, 152-156. https://doi.org/10.4236/jbise.2008.13025

148. Madkan, A., Blank, M., Elson, E., Chou, K.C., Geddis, M.S. and Goodman, R. (2009) Steps to the Clinic with ELF EMF. Natural Science, 1, 157-165. https://doi.org/10.4236/ns.2009.13020

149. Lian, P., Wei, D.Q., Wang, J.F. and Chou, K.C. (2011) An Allosteric Mechanism Inferred from Molecular Dynamics Simulations on Phospholamban Pentamer in Lipid Membranes. PLoS ONE, 6, e18587. 
https://doi.org/10.1371/journal.pone.0018587

150. Liao, Q.H., Gao, Q.Z., Wei, J. and Chou, K.C. (2011) Docking and Molecular Dynamics Study on the Inhibitory Activity of Novel Inhibitors on Epidermal Growth Factor Receptor (EGFR). Medicinal Chemistry, 7, 24-31. https://doi.org/10.2174/157340611794072698

151. Li, J., Wei, D.Q., Wang, J.F., Yu, Z.T. and Chou, K.C. (2012) Molecular Dynamics Simulations of CYP2E1. Medicinal Chemistry, 8, 208-221. https://doi.org/10.2174/157340612800493692

152. Wang, J.F. and Chou, K.C. (2012) Recent Advances in Computational Studies on Influenza a Virus M2 Proton Channel. Mini Reviews in Medicinal Chemistry, 12, 971-978. https://doi.org/10.2174/138955712802762275

153. Zhang, T., Wei, D.Q. and Chou, K.C. (2012) A Pharmacophore Model Specific to Active Site of CYP1A2 with a Novel Molecular Modeling Explorer and CoMFA. Medicinal Chemistry, 8, 198-207. https://doi.org/10.2174/157340612800493601

154. Jia, J., Liu, Z., Xiao, X. and Chou, K.C. (2015) iPPI-Esml: An Ensemble Classifier for Identifying the Interactions of Proteins by Incorporating Their Physicochemical Properties and Wavelet Transforms into PseAAC. Journal of Theoretical Biology, 377, 47-56. https://doi.org/10.1016/j.jtbi.2015.04.011

155. Jia, J., Liu, Z., Xiao, X., Liu, B. and Chou, K.C. (2016) Identification of Protein-Protein Binding Sites by Incorporating the Physicochemical Properties and Stationary Wavelet Transforms into Pseudo Amino Acid Compo sition (iPPBS-PseAAC). Journal of Biomolecular Structure and Dynamics (JBSD), 34, 1946-1961. https://doi.org/10.1080/07391102.2015.1095116

156. Chou, K.C. (2019) Proposing Pseudo Amino Acid Components Is an Important Milestone for Proteome and Genome Analyses. International Journal for Peptide Research and Therapeutics (IJPRT), 26, 1085-1098. https://doi.org/10.1007/s10989-019-09910-7

157. Chou, K.C. (2019) Artificial Intelligence (AI) Tools Constructed via the 5-Steps Rule for Predicting Post-Translational Modifications. Trends in Artificial Intelligence (TIA), 3, 60-74. https://doi.org/10.36959/643/304

158. Chou, K.C. (2019) Impacts of Pseudo Amino Acid Components and 5-Steps Rule to Proteomics and Proteome Analysis. Current Topics in Medicinal Chemistry, 19, 2283-2300. https://doi.org/10.2174/1568026619666191018100141

159. Chou, K.C. (2019) An Insightful Recollection for Predicting Protein Subcellular Locations in Multi-Label Systems. Genomics. (In Press) https://doi.org/10.1016/j.ygeno.2019.08.022

160. Chou, K.C. (2019) Advance in Predicting Subcellular Localization of Multi-Label Proteins and Its Implication for Developing Multi-Target Drugs. Current Medicinal Chemistry, 26, 4918-4943.

https://doi.org/10.2174/0929867326666190507082559 